\title{
EDITORIAL
}

\section{THE CHALLENGE FOR ASTIN IN THE 21st CENTURY}

Perhaps I could start by mentioning two currently fashionable key phrases : "change management" and "teamwork". It is not my concern here to attribute precise meanings to these terms : they are included as being indicative or symptomatic of underlying changes affecting the manner in which non-life insurance is being transacted at the end of the 20th century. Whilst it could be argued that the history of insurance is one of change, and that there is nothing new in the idea of teamwork, I think it is indisputable that, in Western Europe at least, change in the social and economic environments has forced a corresponding rate and depth of change in many aspects of insurance.

To be specific, I need only refer to such developments as the burgeoning market in telesales insurance in the UK, with other countries variously following behind; the significant impact on the UK market of developments in mortgage related insurance; the problems which have beset Lloyds and, in a somewhat different vein, the stream of EC Directives not only having the effect of shaping internal markets, but introducing some degree of convergence between territories in aspects where diversity may have previously been the norm.

Other developments include changes in solvency testing in the US, the securitisation of insurance risks and the increasing prominence given to linking risk arising from both insurance and its supporting assets.

Accompanying what might be regarded as market changes of this kind, the continuing evolution of computing power has brought undreamt-of capability to the desk of the most junior actuary. A consequence has been the continued tipping of the balance between, on the one hand, classical analysis and, on the other, numerical methods and simulation. Of course the old problems have not been force entirely off-stage-rather the onward march of processing capability has unveiled new problems which previously either did not arise in the conditions of the day, or could safely be put in the "too difficult" box with the expectation that competitors would do likewise-if indeed they recognised the problem. If solutions were needed in practice they could be provided by a non-actuarial management.

We now have a situation where what might be regarded as a surge of change is taking place across the insurance markets of the world. In turn, new problems in managing and controlling insurance and reinsurance operations are arising. In company with these developments, the force of competition, which decades ago might have been regarded as a gentlemanly, if not gentle, breeze, has suddenly become a gale.

What does this mean for Astin?

To attempt to answer this, we have to look at the scope of Astin, which, as we all know, is concerned with actuarial studies in non-life insurance. But what do 
"actuarial studies" embrace, either in terms of subject material or nature? Have we stretched the boundaries of the objects of our studies in line with the changing market scenario and the changing capabilities of modern technology? Have we got the right balance between "in-depth" academic studies of very specific topics and more superficial, less "respectable" examinations of a broader subject matter which does not lend itself so conveniently to a "nice" treatment?

Every member of Astin will have his own answers to these questions : perhaps I could try to stimulate discussion by looking again at familiar areas of activity.

For many years-since the formation of Astin-we have been concerned with a traditional subject matter embracing the areas of risk and ruin, moving more recently into such areas as claim reserving and risk costing (as distinct from rating).

If we look at what happens in an actual insurance operation, in arriving at a rate for a risk, it is difficult to deny that each of these areas should be represented. However, in practice, other considerations come into play whose significance may dwarf those mentioned (with the possible exception of claim reserves).

These areas-assuming we are concerned with setting rates in a competitive marketplace-would embrace (to select a few items at random):

- how to relate rates to risk in the presence of classificatory factors : for some of which only limited information, but for others extensive experience, may be available: should we use explicit, purpose built models, neural networks, etc.;

- how to estimate outstanding claims for the purposes of rating, and to reflect risk and other factors in the basis used for claim development, given the existence in some cases of possibly vast historic stores of relevant detailed past experience;

- how to take into account competitors' activities;

- how to take into account more or less well-defined cycles of insurance-related experience;

- how and to what extent to take into account risk and return on assets supporting the insurance activity;

- how to define meaningful objectives, to which rates can be attuned, which reflect the rating cycle, uncertainty of experience, the need to relate risk and return to the performance of other capital markets, etc., etc.

To take another example - after decades of papers on claims reserving, the methodology employed in practice is in most cases, I would guess, extremely basic and subjective. This most fundamental of actuarial activities I suspect suffers from the lack of a generally agreed basic approach which effectively utilises the extent of information available in a systematic way.

Is something going wrong? If Astin was intended and is intended as no more than a group whose objectives either do not include practical usefulness of output, or include it only incidentally, then we could claim all is well. If, on the other hand, as a sub-group of IAA, its objective is to support the progress of actuarial science-and not least actuaries-then I suspect at the very least some of these issues deserve an airing. 
Let me make two suggestions :

- authors of papers to the Workshop Section of AB should be encouraged to write papers which describe problem areas they have encountered, without necessarily offering a solution;

- the Astin Committee itself should take stock of the extent to which

(a) actuaries are moving into less traditional areas of non-life insurance, and the extent to which they have the support of a range of actuarial methodologies.

(b) areas of insurance operation in which actuaries have only peripherally, if at all, been involved, now offer serious actuarial challenges.

The turn of the millennium represents a series of challenging opportunities for the profession - but only if it reaches out an grasps them before others develop the necessary skills.

HARRY REID 